\title{
APROVEITAMENTO DA ÁGUA DE CHUVA PARA IRRIGAÇÃO DO JARDIM EM UM CONDOMÍNIO RESIDENCIAL
}

\author{
Felipe Leite Góes ${ }^{1}$; Cristina T. Pérez² \\ 1SENAI CIMATEC, Av. Orlando Gomes, 1845 - Piatã; Salvador/Bahia; \\ felipe_Ipgoes@hotmail.com \\ ${ }^{2}$ SENĀI CIMATEC, Av. Orlando Gomes, 1845 - Piatã; Salvador/Bahia; \\ cristina.perez@fieb.org.br
}

Resumo: O presente trabalho tem como objetivo avaliar a viabilidade da utilização de um sistema de aproveitamento de água da chuva para irrigação de um jardim em um condomínio residencial localizado na cidade de Salvador/Bahia, a partir da análise dos dados referentes a fatores como demanda, precipitação e área de coleta. As principais etapas do estudo foram: (1) identificação do objeto de estudo; (2) levantamentos de dados, tais como: índice pluviométrico, área disponível de cobertura e consumo de água utilizada para irrigação; (3) cálculo de volume de água captado mensal; e (4) realização do dimensionamento do reservatório para captação de água de chuva. Como principal resultado, encontrou-se que $100 \%$ da água utilizada para irrigação pode ser água reutilizada de origem pluvial, totalizando uma economia de 5.000 litros mensais, o que representa $3 \%$ do consumo total do condomínio.

Palavras-Chave: água; chuva; aproveitamento; irrigação.

\section{REUSE OF RAINWATER IN A RESIDENTIAL CONDOMINIUM FOR IRRIGATION OF OUTDOOR PLANTS}

\begin{abstract}
The present study aims to evaluate the feasibility of using a rainwater harvesting system for irrigation of a garden in a residential condominium, from the analysis of data on the factors of demand, precipitation and collection area. The main steps of the study were: (1) identification of the object of study; (2) data collections, such as: rainfall index, available area of coverage, and water consumption used for irrigation; (3) calculation of monthly water abstraction; and (4) design of the reservoir to collect rainwater. As a main result, it was found that $100 \%$ of the water used for irrigation can be recycled water of rainwater, totaling a saving of 5,000 liters per month, resulting on $3 \%$ of the total consumption of the condominium.
\end{abstract}

Keywords: water; rain; reuse; irrigation. 


\section{INTRODUÇÃO}

$\mathrm{Na}$ atualidade a preocupação com a conservação dos recursos naturais é cada vez mais recorrente. A água vem sendo cada vez mais tratada como assunto de extrema importância, afinal, trata-se de um elemento verdadeiramente necessário para a vida. No entanto, a sua utilização incorreta por séculos vem sendo notada com o passar dos anos, em virtude da sua crescente escassez [1].

Tendo em vista que a água é considerada um recurso natural limitado e imprescindível à vida, questões sobre a conservação e preservação dos recursos hídricos vêm sendo cada vez mais destacadas [1].

A sociedade utiliza a água para praticamente todas as atividades, seja para o cultivo agrícola, para a criação de animais, para o funcionamento de indústrias, fabricação de produtos, abastecimento da população, etc. Sendo assim, elemento vital para o desenvolvimento econômico e tecnológico de nossa sociedade.

Além do pouco volume de água doce disponível no planeta, outro fator agravante está relacionado à forma como ela vem sendo utilizada pela população mundial. Com relação a esse ponto, deve ser destacado que a agricultura é a responsável pelo maior consumo de água no planeta (70\%), seguida pelas indústrias $(22 \%)$ e, por último, pelo consumo doméstico e comercial (8\%) [2].

Em busca da diminuição do consumo de água doce no planeta, algumas técnicas são aplicadas com o objetivo de estimular a população a aderir a métodos de reaproveitamento dos recursos naturais, capazes de gerar considerável economia financeira, além de minimizar os impactos produzidos no meio ambiente. Técnicas de reuso ou o aproveitamento da água das chuvas vem sendo cada vez mais utilizadas para fins não potáveis. Por meio desses métodos, a água da chuva captada pode ser aproveitada, para a irrigação de jardins, lavagem de automóveis e de calçadas. Esse sistema pode ser implantado em qualquer residência de forma simples e geralmente com baixo custo [1].

Assim, tendo em vista a importância da água para a população, o presente trabalho tem por objetivo avaliar o potencial de economia de água que pode ser obtido através da implantação de um sistema de aproveitamento de água pluvial para irrigação do jardim de um condomínio composto por oito casas.

\section{METODOLOGIA}

Para atingir o objetivo proposto, foi adotado o método Estudo de Caso [3] tendo sido seguidas durante a sua realização, as seguintes etapas: (1) identificação do objeto de estudo; (2) coleta de dados; e (3) cálculo de volume de água captado mensal. 


\subsection{Identificação do objeto de Estudo}

Para o presente estudo foi utilizado, como objeto de estudo, um condomínio localizado no bairro de Jaguaribe, na cidade de Salvador/BA, formado por 08 (oito) casas distribuídas em dos blocos. A partir da análise da planta baixa do condomínio, é possível verificar que a área do terreno possui um total de $1249,5 \mathrm{~m}^{2}$, sendo que aproximadamente $200 \mathrm{~m}^{2}$ correspondem à delimitação do jardim, local que será utilizado para determinar a área de irrigação (área sinalizada na cor verde na Figura 1). Os blocos do condomínio possuem uma área de telhado de $431 \mathrm{~m}^{2}$ (área sinalizada na cor vermelho na Figura 1), que servirá para calcular a captação da água pluvial.

Figura 1. Planta baixa do condomínio residencial objeto de estudo

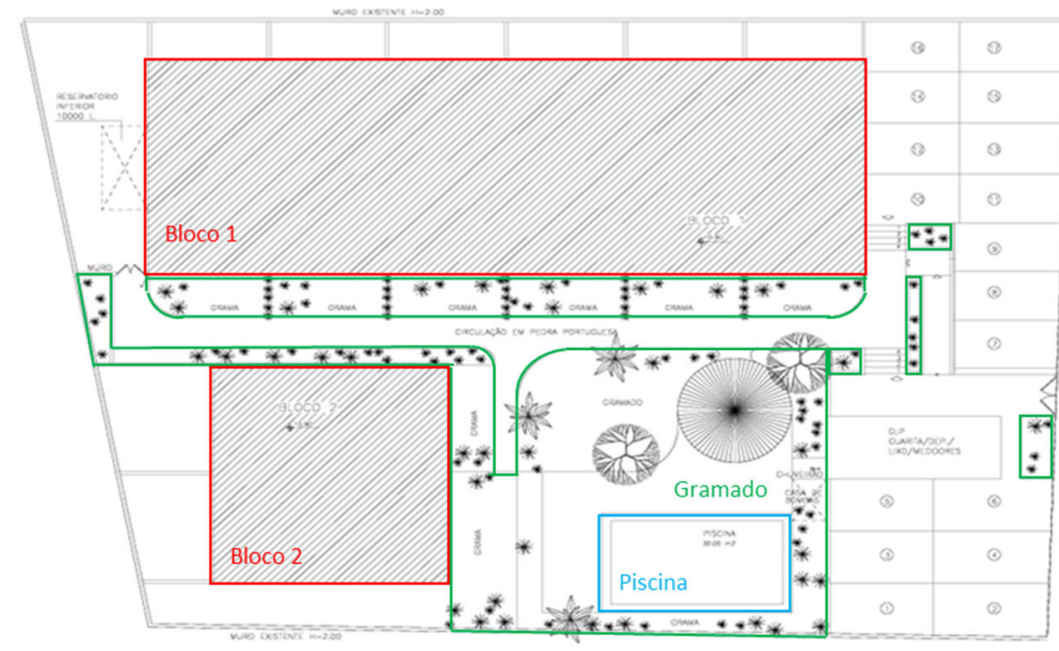

Fonte: Os autores

\subsection{Coleta de dados}

A etapa de coleta de dados visou identificar os valores referentes à: (1) área disponível para a coleta de água; (2) dados pluviométricos; e (3) consumo de água utilizada na irrigação.

\subsection{1. Áreas disponíveis para a coleta de água}

A partir do estudo da planta baixa do empreendimento (Figura 1), verifica-se que o telhado possui uma área $\left(431 \mathrm{~m}^{2}\right)$ duas vezes maior que a do jardim $\left(200 \mathrm{~m}^{2}\right)$, o que representa um fator de extrema importância para a possibilidade de armazenamento da água da chuva. Para o alcance do volume de água da chuva aproveitável deve ser utilizado o Coeficiente de Runoff ou Coeficiente de Escoamento, que representa a relação entre o volume total precipitado e o volume total de escoamento superficial, no qual, irá variar de acordo com a superfície [4]. No tocante a este ponto, é importante mencionar que, para efeito de cálculo, o volume de água da chuva que será aproveitado não será o mesmo que o volume de precipitação [5]. 
O telhado do condomínio estudado é composto por telhas cerâmicas, sendo assim, o coeficiente de escoamento superficial (Coeficiente de Runoff) adotado será de "0,8" [5].

Tabela 1. Coeficiente de Runoff médios para superfícies de cobertura

\begin{tabular}{|l|l|l|l|l|}
\hline Material & $\begin{array}{l}\text { Telhas } \\
\text { cerâmicas }\end{array}$ & $\begin{array}{l}\text { Telhas } \\
\text { esmaltadas }\end{array}$ & $\begin{array}{l}\text { Telhas corrugadas de } \\
\text { material Plástico }\end{array}$ & Plástico \\
\hline Coeficiente De Runnof & 0,8 a 0,9 & 0,8 a 0,9 & 0,8 a 0,9 & 0,8 a 0,9 \\
\hline
\end{tabular}

Fonte: [1]

\subsubsection{Dados pluviométricos}

Para a coleta de dados dos índices pluviométricos foram utilizados os dados fornecidos pelo Instituto Nacional de Meteorologia (INMET) [6], os quais correspondem aos anos de 1991 a 2017, um total de 27 (vinte e sete) anos, da cidade de Salvador/BA. Os dados apresentados pelo INMET foram captados por meio de uma estação meteorológica que está localizada no bairro da Ondina-Salvador/BA. Local que se encontra a uma distância relativamente próxima (aprox. 18km) ao local de estudo. Segundo dados divulgados pelo INMET, os índices pluviométricos da cidade de Salvador/BA apresentam uma média de 1.824,16 milímetros por ano, sendo maio o mês que apresenta a maior média de precipitação, cerca de 301,63 milímetros $(\mathrm{mm})$, enquanto o mês de dezembro registrou o menor índice, cerca de $62,02 \mathrm{~mm}$ (Figura 2).

Figura 2. Precipitação média por mês (1991 a 2017)

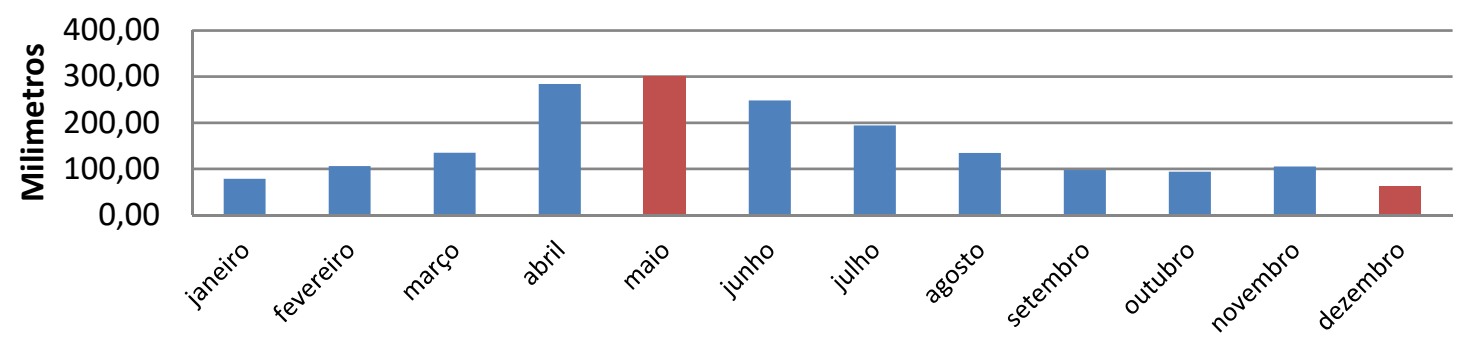

Fonte: [6]

\subsubsection{Consumo de água utilizada na irrigação}

O condomínio em estudo possui apenas um medidor, sendo o consumo de água compartilhado entre todas as 08 (oito) residências. Além disso, há o gasto resultante da utilização de água nas áreas comuns, o que inclui a irrigação dos jardins. No que tange ao consumo do recurso hídrico, foi realizado o cálculo da média do consumo de água do condomínio durante o período de 9 (nove) meses, chegando-se ao valor de 143.000 litros por mês (Figura 3). 
Figura 3. Consumo de água (litros) do condomínio objeto de estudo

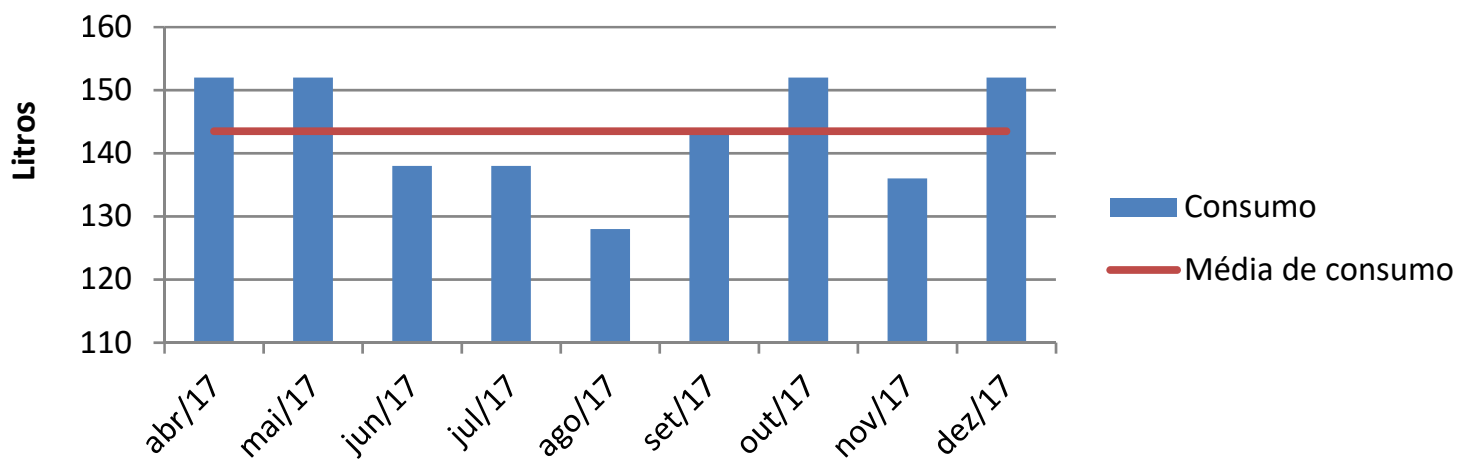

Fonte: Os autores

Para o cálculo do consumo de água utilizado para irrigação (Tabela 2) foram realizadas as seguintes atividades: (a) medição da vazão da torneira utilizada para a irrigação, a partir da observação do número de litros gastos por segundo; (b) cálculo da média de tempo gasto para a execução deste serviço, para isso foi cronometrado o tempo de uso durante a atividade; e (c) coleta do número de vezes que é realizada a irrigação, informação obtida por meio da realização de uma entrevista informal com o funcionário responsável por irrigar o jardim.

Tabela 2. Atividades e fontes de evidência utilizadas para o cálculo do consumo de água utilizado para irrigação.

\begin{tabular}{|l|c|c|}
\hline Atividades realizadas & Fonte de evidência & Valores obtidos \\
\hline (a) Medição da vazão da torneira & Observação direta & 1 litro/7 segundos \\
\hline (b) Cálculo do tempo médio gasto & $\begin{array}{c}\text { Cronometragem do tempo de } \\
\text { irrigação }\end{array}$ & 40 min e 26 seg \\
\hline (c) Identificação número de vezes & $\begin{array}{c}\text { Entrevista informal com } \\
\text { funcionário responsável }\end{array}$ & $3 /$ semana \\
\hline
\end{tabular}

Fonte: Os autores

O valor obtido da vazão da torneira utilizada para irrigação, após uma série de testes realizados, foi de 1 litro a cada 7 segundos. No que diz respeito ao cálculo da média do tempo de irrigação, foi cronometrado o tempo utilizado em 15 (quinze) irrigações, chegando-se ao tempo médio de, aproximadamente, 40 minutos e 26 segundos. Com relação ao número de vezes que a referida atividade é realizada no condomínio, foi feita uma entrevista com o funcionário responsável, obtendo-se a informação de que a irrigação do jardim é realizada três vezes por semana.

Para o cálculo do consumo de água mensal na irrigação foi utilizada a Equação 1. O volume mensal de água consumido é multiplicado pelo número de dias em que são realizadas irrigações no mês.

$$
V_{m}=\left(V_{z} \times T_{\text {irrig }}\right) \times N
$$


Onde:

$$
\begin{aligned}
& V_{m}=\text { Volume mensal }(L) \\
& V_{z}=\text { Vazão média da torneira }(L / s) \\
& T_{i r r i g}=\text { Tempo de irrigação médio }(s) \\
& N=\text { Número de dias de irrigações no mês (dias) }
\end{aligned}
$$

\subsection{Cálculo de volume de água captado mensal}

Para o cálculo do volume mensal de água captado pela cobertura foi utilizada a Equação 2.

$$
V_{\text {cap }}=C \times A \times I_{m}
$$

Onde:

$$
\begin{aligned}
& V_{\text {cap }}=\text { Volume captado Mensal }(L / m e ̂ s) \\
& C=\text { Coeficiente de Runoff } \\
& A=\text { Area de Captação }\left(\mathrm{m}^{2}\right) \\
& I_{m}=\text { Precipitação mensal }(\mathrm{mm})
\end{aligned}
$$

\section{RESULTADOS E DISCUSSÃO}

A partir dos dados fornecidos pelo INMET, verifica-se que do ano de 1991 a 2017, o mês com menor índice de chuvas na região foi o mês de dezembro. Por se tratar do mês de menor precipitação, caracteriza-se como o mês de menor captação de água para utilização do sistema, portanto o mesmo será usado para efeito de cálculo, servindo como base para o dimensionamento do reservatório de armazenamento da água da chuva, que poderá ser utilizado para a irrigação, com vistas a diminuir o consumo de água potável.

Ao ser multiplicada a quantidade de litros por segundo pelo valor médio de tempo gasto para realizar a irrigação do jardim, chegou-se ao gasto de 347 litros de água por dia, obtendo-se um total de, aproximadamente, 4.159 litros de água por mês, haja vista que são feitas 12 (doze) irrigações mensais.

Durante o mês de dezembro, que servirá de referência, a média calculada, a partir dos dados presentes no INMET, foi de $61,22 \mathrm{~mm}$ de precipitação. Logo, após ser multiplicada a área de telhado pela média de precipitação foi obtida a quantia de 22.428 litros de água pluvial em potencial para armazenamento em um único mês.

Para efeito de cálculo, o volume de água precipitado não será o mesmo que o volume de água captado. O valor do volume de água captado em um mês (22.428 I) deve ser multiplicado pelo Coeficiente de Runoff de 0.8 (telha do local em estudo é do tipo cerâmico). Chegando-se ao valor real captado de 17.942 litros de água.

Dessa forma, pode-se dizer que após os cálculos feitos, utilizando as Equações 1 e 2, chegou-se à quantia de aproximadamente 4.159 litros de águapor mês destinada para irrigação, isso no mês com menor índice de precipitação. Portanto, um tanque de aproximadamente 5.000 litros, exclusivo para o armazenamento da água 
da chuva, seria suficiente para garantir a irrigação do jardim por um mês. O aproveitamento de 5000 litros de água de chuva supõe uma economia de $3 \%$ dos 143.000 litros da água gasta pelo condomínio por mês.

O restante da água da chuva coletado (12.942 litros, representando $72 \%$ da água coletada) poderá ser descartado na rede de águas pluviais na rua, já que o condomínio do presente estudo não possui área suficiente para armazenar o volume total de água captado. Caso considere-se ser utilizado para o fins potáveis, seria necessário a construção de um sistema apropriado para o tratamento desta água.

\section{CONCLUSÃO}

Comparando-se o consumo de água utilizado na irrigação do jardim por mês com o potencial de captação da água da chuva, constata-se que seria viável a adoção do aproveitamento da água de chuva no condomínio objeto de estudo, podendo-se, inclusive, aumentar a quantidade de dias de irrigação de três para cinco dias durante a semana.

O gasto de água destinada para irrigação de todo o jardim é facilmente suprido pelo potencial de captação da água da chuva, isso, tomando-se como base o estudo de 27 anos de medições dos índices pluviométricos da cidade de Salvador/BA.

Após todos os cálculos realizados, constatou-se de forma contundente a viabilidade, em termos de volume métrico de água, da implantação de um sistema de reaproveitamento de água pluvial capaz de contribuir para a diminuição do consumo desse recurso natural de extrema relevância para a continuidade da vida no planeta. Assim, evidencia-se ser possível que a água utilizada para a irrigação seja $100 \%$ de origem pluvial.

\section{REFERÊNCIAS}

${ }^{1}$ TOMAZ, Plínio. Curso de Manejo de águas pluviais. Capítulo 2. Método Racional.São Paulo. 2013.

${ }^{2} \mathrm{~A}$ ONU e a água, disponível em: <https://nacoesunidas.org/agencia/fao/>, acesso em: 13, Dez, 2017.

${ }^{3}$ YIN, Roberto K. Estudo de caso: planejamento e métodos. $2^{\mathrm{a}} \mathrm{Ed}$. Porto Alegre. Editora: Bookmam. 2001.

${ }^{4}$ NBR 15527, ABNT. Água de chuva. Aproveitamento de água de chuva de coberturas para fins não potáveis.

${ }^{5}$ TOMAZ, Plínio. Aproveitamento de água de chuva. Aproveitamento de agua de chuva para areas urbanas e fins não potáveis. 2a Ed. Editora: Navegar Editora. 2005.

${ }^{6}$ INMET, Instituto Nacional de Meteorologia. Gráficos de Precipitação. Disponível em: <http://www.inmet.gov.br/portal/>, acesso em: 21, Dez, 2017. 